\title{
Ensino por Projetos: explorando conceitos de geometria numa perspectiva interdisciplinar
}

Beatriz S. C. Cortela

\section{Resumo}

Trata-se do relato de uma experiência de ensino realizada com alunos de $3^{\mathrm{a}}$ série do Ensino Médio da rede de ensino pública paulista, com duração de quatro meses. O projeto foi elaborado visando atingir, de forma mais específica, as competências e habilidades da área de Matemática para a referida série, a partir de um trabalho interdisciplinar, dentro da abordagem Histórico-Crítica, explorando outras inteligências, além da lógico-matemática, tais como a espacial, a linguística e a interpessoal. A ideia foi a de propiciar a aprendizagem de conteúdos ligados à construção de sólidos geométricos e ao cálculo de suas áreas e volumes explorando também conteúdos da área de linguagens, arte e história, a partir de diversas atividades, tais como a produção de artigos de opinião e de painéis artísticos para uma exposição de arte, utilizando a técnica de Assemblage ${ }^{1}$, associada ao Cubismo. Esta dinâmica de trabalho permitiu que os estudantes percebessem como os conhecimentos sobre a Geometria foram se estruturando ao longo do tempo, como estão interligados numa espécie de rede que vai se expandindo, ligando assuntos e áreas de conhecimentos que se complementam. Permitiu também que estes trabalhassem em ritmos diferenciados, estabelecessem formas de trabalho em grupo e desenvolvessem diferentes habilidades, em comparação a uma abordagem mais tradicional do conteúdo matemático citado.

Palavras-chave: projeto de ensino, interdisciplinaridade, inteligências múltiplas, abordagem Histórico-Crítica.

${ }^{1}$ Técnica artística baseada no princípio de que todo e qualquer material pode ser incorporado a uma obra de arte, criando um novo conjunto, sem que esta perca o seu sentido original. É uma junção de elementos em um conjunto maior de modo que, ao se utilizar de diversos materiais como papéis, tecidos, madeira "colados" a uma tela, o artista conseguia ultrapassar as limitações da superfície, criando uma junção de pintura com escultura. 


\section{Introdução}

O trabalho daquele que ensina é complexo uma vez que ocorre em situações singulares, incertas e instáveis (Schön, 2000). Também, porque não se trata de o professor simplesmente, "[...] se apoiar em conhecimentos objetivos que produzam concretamente tecnologias eficazes nas situações de trabalho" (Tardif, 2002, p.265), como sugerem os modelos de formação de professores baseados na racionalidade técnica.

Concordando com Henández e Ventura (1998, p.17), "Qualquer experiência educativa é singular [...]”, ou seja, cada contexto de aprendizagem comporta um conjunto de fatos, circunstâncias, intercâmbios e relações que ultrapassam aquilo que acontece num laboratório. Assim também ocorre com os experimentos de ensino que, quando reproduzidos, podem não apresentar os mesmos resultados. Destarte, a intenção deste artigo não é apresentar este relato de experiência com a intenção de oferecer uma "receita" para o ensino. A ideia é, a partir de sua divulgação, possibilitar a discussão, estabelecimento de pontos de conexão com as outras práticas e visualizar novas possibilidades de trabalho. A intenção é também a de teorizar sobre elas, numa tentativa de legitimar saberes experienciais no sentido de transformá-los em saberes da ação pedagógica (GAUTHIER, 1998).

Com o objetivo de contextualizar o problema que desencadeou este projeto de ensino, torna-se importante a descrição de alguns fatos e situações vivenciadas. Desde 2008, a Secretaria da Educação do Estado de São Paulo propôs um currículo básico para as escolas de níveis fundamental e médio. De acordo com SÃO PAULO (2012), este currículo apoia-se nos seguintes princípios centrais: a escola que aprende; o currículo como forma de cultura; as competências como eixo das aprendizagens e a contextualização no mundo do trabalho.

Com vista à operacionalização do mesmo, a rede paulista vem trabalhando, nos últimos anos, utilizando-se de um sistema apostilado, elaborado por especialistas, e composto por dois tipos de cadernos: o do aluno e do professor. No decurso do ano letivo, os alunos recebem dois cadernos referentes às disciplinas que compõem o currículo e que contêm atividades a serem desenvolvidas durante os dois semestres. Já para os professores, a reposição destes cadernos não ocorre ano a ano, mas somente quando há perdas ou contratação de novos docentes. A Secretaria de Estado também disponibiliza aos alunos, através do Plano Nacional do Livro Didático (PNLD), livros que são escolhidos pelo corpo docente de cada instituição de ensino.

Os cadernos de Matemática se mantêm praticamente inalterados ao longo dos anos (2008-2016). Apesar de discordarmos, em muitos pontos, do modo como os conteúdos são apresentados aos alunos, muitas vezes sem explorar adequadamente a teoria, e da forma abrupta como foram implementados pela rede de ensino, reconhecemos a importância dos temas neles desenvolvidos e algumas das metodologias de ensino propostas, baseadas 
naquelas sugeridas no documento que trata das Orientações para o Ensino Médio (BRASIL, 2006).

Registramos, porém, que eventualidades de cunho burocrático prejudicam o planejamento e o uso adequado destes cadernos. Por exemplo: no último bimestre do ano de 2009, estudantes de $2^{\mathrm{a}}$ série do ensino médio de uma Regional de Ensino do interior paulista não receberam, em tempo hábil, a entrega do $4^{\circ}$ caderno de Matemática. Naquela época, cada disciplina recebia quatro cadernos, um para cada bimestre, diferente do que ocorre hoje, que são dois cadernos, um para cada semestre. Para minimizar os prejuízos acarretados na aprendizagem daqueles conteúdos, a Secretaria de Estado solicitou que este caderno fosse trabalhado pelos professores da série posterior, ou seja, no primeiro bimestre do ano letivo de 2010, sem deixar de cumprir todo o programa referente à $3^{\mathrm{a}}$ série.

Tal exigência, apesar de coerente, representou uma dificuldade quanto ao tempo de trabalho disponível para tamanha quantidade de conteúdo a serem desenvolvidos naquele bimestre. O projeto de ensino aqui descrito foi elaborado a partir desta situação-problema vivida por uma das autoras deste trabalho. Responsável por ministrar a disciplina de Matemática, seu objetivo maior era o de estimular a percepção dos estudantes acerca da presença de aplicações dos conteúdos matemáticos no dia-a-dia, cujo enfoque não se restringia, apenas, às atividades escolares e/ou econômicas. No desenvolvimento de seu trabalho, visava mostrar que os conteúdos matemáticos também são necessários e estão presentes em outros campos do conhecimento, tal como nas artes, na arquitetura, entre outros, considerando-os como resultantes de um conhecimento social e historicamente construído, em concordância com as Orientações Curriculares (BRASIL, 2006).

A organização dos conteúdos básicos em Matemática (SÃO PAULO, 2012) se faz em três grandes blocos temáticos e de uma maneira articulada, de modo que estes se interpenetram permanentemente, sendo impossível tratar de cada um deles sem a participação dos demais: Números, Geometria e Relações. No bloco Geometria são tratados conceitos diretamente ligados à percepção de formas (figuras planas e espaciais), com a construção e representação de formas geométricas, que faculta aos alunos a percepção de concepções de espaço que lhes servem de apoio para a compreensão do mundo físico.

No entanto, essas concepções podem variar conforme o processo formativo pelos quais o estudante tenha ou esteja passando. "E mesmo as concepções mais inovadoras têm como referência percepções ou construções já realizadas, renovando seus pressupostos ou transcendendo seus limites" (SÃO PAULO, 2012, p.42).

Isso justifica as orientações do documento, cuja ideia é trabalhar com os conteúdos de forma espiralada, ou seja, os temas são aprofundados durante todo o processo de 
formação do aluno, forma de organização do conteúdo que permite renovar antigos pressupostos e transcender limites do aprendizado dos estudantes.

No intuito de articular as solicitações feitas em relação às orientações curriculares, os conteúdos de Geometria espacial e as determinações da gestão escolar, vislumbramos como possibilidade do desenvolvimento de um projeto interdisciplinar, cujas atividades seriam realizadas, em grande parte, de forma extraclasse. A carga horária da disciplina de Matemática era de 5 horas- aula semanais, cada uma de 50 minutos. Para o desenvolvimento do projeto foram reservadas duas horas-aula semanais, enquanto que nas demais eram trabalhados os conteúdos referentes ao $1^{\mathrm{o}}$ bimestre da $3^{\mathrm{a}}$ série do ensino médio, que trata da Geometria Analítica. Em relação a Língua Portuguesa e Artes, foram dedicadas duas horasaula quinzenais.

\section{O processo de construção do projeto de ensino}

Vários autores, entre eles Hernández (1998), afirmam que trabalhar com conteúdos de maneira interdisciplinar permite que os alunos percebam como os conhecimentos foram se estruturando ao longo do tempo; como estão interligados numa espécie de rede que vai se expandindo, ligando assuntos e áreas de conhecimentos que se complementam, superando uma visão fragmentada da realidade, que é reforçada quando se abordam os conteúdos de uma maneira tradicional.

Importante ressaltar, como considera Kuenzer (2007), que o modo como a Matemática vem sendo tradicionalmente trabalhada nas escolas, está muito distante daquela utilizada como suporte das atividades cotidianas. Ou seja, toda a tecnologia da informação, tais como cartões magnéticos, código de barras, programas de computadores, entre outras, faz uso de uma Matemática mais complexa, ou seja, se utilizando de uma linguagem mais formal e peculiar.

Muitas pessoas são usuárias destas tecnologias, mas poucas têm noção sobre como estes conhecimentos foram e vão sendo construídos ao longo do tempo, por diferentes pessoas e decorrentes de diferentes interesses.

É importante que o aluno perceba o uso da ferramenta matemática em funcionamento em situações simples a partir das quais ele possa construir conceito, identificar e perceber as propriedades e estabelecer relações desenvolvendo capacidades para transferir suas conclusões para situações análogas ou situações mais sofisticadas e complexas, adaptando e ampliando seus conhecimentos num processo de permanente aprendizado (KUENZER, 2007, p.163).

Hernández e Ventura (1998) consideram que o ensino por projeto parte de um enfoque globalizador, centrado na resolução de problemas significativos; propõe atividades 
abertas, permitindo que os alunos estabeleçam seus planos de trabalho, cuja sequência segue o nível de abordagem e de aprofundamento necessário. Desta forma, transfere para o estudante, em grande parte, a responsabilidade pela própria aprendizagem, na medida em que o coloca como autor principal do processo.

De acordo com os autores supracitados, para que os estudantes consigam atingir esse objetivo, as atividades devem ser elaboradas visando conciliar as diferentes vertentes do processo de ensino, o que demanda esforços dos professores no sentido de garantir que o projeto seja bem planejado, com objetivos, metodologias, atividades, instrumentos e critérios de avaliação articulados.

Este projeto visou atingir, de forma específica, as competências e habilidades da área de Matemática almejadas para o tema Geometria Métrica Espacial: elementos de geometria e posição abordando-os a partir de uma perspectiva interdisciplinar e explorando outras inteligências, tais como: a espacial, a linguística e interpessoal (GARDINER, 1994), para além do raciocínio lógico-matemático. Para tanto, a ideia foi articular estas competências a outras, ligadas a diferentes áreas do conhecimento.

A disponibilidade de um grupo de professoras em elaborar e executar um projeto de ensino interdisciplinar, que atendesse aos objetivos específicos propostos em cada uma das diferentes disciplinas por elas ministradas (Matemática, Artes e Língua Portuguesa), foi algo inusitado na escola, e possibilitou explorar a abordagem dos conteúdos em perspectivas menos tradicionais, a partir de diferentes habilidades.

Esse grupo estabeleceu como objetivos, a saber: conhecer, planificar, construir diferentes sólidos geométricos, efetuando cálculos de áreas e volumes; compreender as relações entre o desenvolvimento da Matemática e a construção dos grandes monumentos históricos; conhecimentos da técnica Assemblage e suas relações com o Cubismo. Como resultado, os estudantes foram orientados a realizar pesquisas sobre temas propostos, escrever um artigo de opinião, elaborar um painel artístico, auxiliar na organização e desenvolvimento de uma exposição de arte na escola, fotografando e registrando estes momentos.

Para colocar o projeto em prática foi preciso delinear as estratégias de execução e avaliação dos resultados. É o que descreveremos a seguir.

\section{Planejamento do projeto}

Utilizando parte do tempo destinado às Atividades de trabalho pedagógico coletivo (ATPC), realizados semanalmente com a presença do coordenador pedagógico da escola, as professoras elaboraram as diferentes etapas do trabalho. Discutiram a fundamentação teórica que melhor contemplava os objetivos referentes às diversas fases do projeto; estabeleceram 
desde a forma como os conteúdos seriam abordados até a elaboração dos instrumentos e critérios de avaliação para cada uma delas e do projeto como um todo. Também, durante o desenvolvimento do projeto, foi preciso reorganizar o trabalho, discutir novas questões e este espaço de reflexão esteve aberto para isso.

Optou-se por trabalhar na perspectiva da teoria Histórico-Crítica. De acordo com Gasparin (2009), o processo de planejamento de um projeto dentro desta abordagem deveria ser iniciado a partir de problemas sociais existentes na comunidade ou na sociedade. No entanto, o mesmo autor enfatiza que essa linha de raciocínio e de trabalho se tornam inviáveis em razão da estrutura organizacional da maioria das escolas públicas, uma vez que os conteúdos já estão definidos antes do início do ano letivo pelas Secretarias, sendo iguais para todas as escolas do ensino público paulista, independente das idiossincrasias presentes. Aponta, o autor, que estes são fatores limitantes, certamente, mas que não inviabilizam uma proposta desta natureza.

Gasparin (2009) considera também que o planejamento pode ser iniciado pela listagem de conteúdos a serem trabalhados e pela definição dos objetivos a serem alcançados, levando-se em conta que o ensino é uma atividade intencional. Assim, este processo é composto por uma sequência de atividades desenvolvidas com vistas à assimilação de conhecimentos e desenvolvimento de habilidades através das quais os alunos, de forma ativa, aprimoram diferentes capacidades cognitivas e cognoscitivas, tais como: observação, análise, síntese, entre outras. Neste sentido, considera que ensinar e aprender são faces de um mesmo processo que se realiza em torno dos conteúdos, sob a coordenação do professor, num movimento mediador.

Algumas das perguntas que orientaram as docentes na construção do presente projeto de ensino foram as mesmas sugeridas por Vasconcellos (2005):

1- Como o ensino destas disciplinas ou conteúdos podem ajudar nossos alunos a compreenderem o mundo que os cercam, contribuindo para dar sentido às coisas?

2- Como eles podem usufruir de um patrimônio cultural acumulado pela humanidade a partir do ensino de diferentes áreas do conhecimento?

3- Como podem transformar-se, ou ainda, como podem transformar o contexto que os cercam a partir do que aprendem?

Após a reflexão sobre estas perguntas, as quatro professoras envolvidas na elaboração do projeto buscaram, entre os conteúdos de suas disciplinas, aqueles que seriam relevantes no contexto do projeto. Para tanto, fizeram uso do seguinte esquema: 
Quadro 1: Tipos de Conteúdos

\begin{tabular}{|c|c|c|c|}
\hline Tipo & Dimensão & Significado & Abrangência \\
\hline Conceitual & "saber" & $\begin{array}{ll}\text { Representações } & \text { ou } \\
\text { conteúdos } & \text { de } \\
\text { consciência } & \end{array}$ & $\begin{array}{l}\text { Conhecimentos de fatos, fenômenos, } \\
\text { conceitos, princípios, leis, saberes, } \\
\text { imagens, esquemas, informações. }\end{array}$ \\
\hline$\widehat{\Uparrow t}$ & $\widehat{\prod}$ & $\widehat{\jmath}$ & $\widehat{\sqrt{b}}$ \\
\hline Procedimental & $\begin{array}{l}\text { "saber } \\
\text { fazer" }\end{array}$ & $\begin{array}{l}\text { Mecanismos } \\
\text { operatórios }\end{array}$ & $\begin{array}{l}\text { Domínio de habilidades (savoir-faire), } \\
\text { competências, aptidões, procedimentos, } \\
\text { capacidades, método de pesquisa, } \\
\text { desenvolvimento de operações mentais, } \\
\text { hábitos de estudo. }\end{array}$ \\
\hline 介 & $\widehat{\sqrt{ }}$ & $\widehat{\Uparrow}$ & $\widehat{\Uparrow}$ \\
\hline Atitudinal & $\begin{array}{l}\text { "ser, saber } \\
\text { e ser" }\end{array}$ & $\begin{array}{l}\text { Disposições do } \\
\text { sujeito; modos de agir, } \\
\text { sentir e se posicionar }\end{array}$ & $\begin{array}{l}\text { Envolvimento, interesses, atitudes, } \\
\text { posturas, valores, posicionamentos, } \\
\text { convicções, preocupações, normas, } \\
\text { regras, vontades. }\end{array}$ \\
\hline
\end{tabular}

Fonte: Vasconcellos, 2005, p.141.

Os recursos materiais são os meios utilizados pelos professores para orientar a aprendizagem dos estudantes, sendo o livro didático um deles. Defendemos que deva ser usado como complemento do trabalho, um apoio teórico visando o preenchimento de diferentes lacunas de aprendizagem, que estão sempre presentes, em diferentes níveis. Também a pesquisa na internet, orientada para fontes confiáveis, é um excelente recurso didático, uma vez que esta ferramenta faz uso de imagens, remete a outros links e "fala" uma linguagem própria que se mostra bastante eficiente com o público-alvo deste projeto. Mas, faz-se necessário que os alunos aprendam a discernir informações, dentre tantas disponíveis na rede, aquelas que são confiáveis e podem gerar novos conhecimentos. Para tanto, uma busca prévia deve ser feita pelos professores, visando orientar os estudantes em suas pesquisas, direcionando-os para sites adequados. Essa habilidade a ser alcançada vai ao encontro da proposta inicial do projeto, que perpassa pela análise crítica das informações que chegam até eles.

A síntese das informações consiste no próximo passo. Caracteriza-se pelo momento em que os estudantes precisam expressar, de diferentes formas, aquilo que foi aprendido, ou seja, a catarse: a passagem da síncrese à síntese. Como considera Gasparin (2009, p.126)

$\mathrm{Na}$ catarse o educando é capaz de situar e entender as questões sociais postas no início e trabalhadas nas demais fases, ressituando o conteúdo numa nova 
totalidade social e dando à aprendizagem um novo sentido. Percebe, então, que não aprendeu apenas um conteúdo, mas algo que tem significado e utilidade em sua vida [...].

Lembrando Vygotsky (1989, p.66), num primeiro momento “[...] é necessário abstrair, isolar elementos e examinar os elementos abstratos separadamente da totalidade da experiência concreta que fazem parte.”, ou seja, fazer a análise. Mas, somente este processo não é suficiente: “[...] na verdadeira formação de conceitos, é igualmente importante unir e separar: a síntese deve combinar-se com a análise.”

Assim, um simples "recortar-colar" do texto pesquisado não representa este processo e, neste sentido, as professoras buscaram não somente mediar o processo de pesquisa, mas também orientar as leituras e a composição dos textos-síntese, a partir de perguntas-chave, seguidas por devolutivas realizadas em sala de aula.

Quanto aos instrumentos e critérios de avaliação, Vasconcellos (2005, p.142) considera que se deve "[...] definir bem as regras do jogo da avaliação com os alunos, para evitar criar ansiedade e desconfiança na relação pedagógica”. No caso de se trabalhar com notas ou conceitos, é importante deixar claro os instrumentos e critérios adotados. Ainda nesse sentido, Kuenzer (2007) argumenta que a avaliação deve ser um indicativo da eficiência e da coerência, visando promover mudanças comportamentais; ela deve apontar mudanças de atitudes, assim como para as competências que foram adquiridas ou desenvolvidas com o programa de atividades proposto pelo projeto.

Deste modo, para além do acúmulo de algoritmos ou de conhecimentos restritos ao uso deles, fez-se necessário elaborar alguns parâmetros de avaliação para os trabalhos que conseguissem abarcar as diferentes maneiras pelas quais os estudantes: construíram conhecimentos; o desenvolvimento de distintas habilidades ao executarem as tarefas que lhes foram solicitadas; a capacidade de trabalhar em grupo; o respeito às diferenças individuais; a organização e o cumprimento dos cronogramas. Segundo Hernández e Ventura (1998, p. 65), esses elementos caracterizam uma avaliação centrada nas relações e nos procedimentos.

Percebe-se que esses critérios descritos são de cunho qualitativo, relevantes para a avaliação a ser realizada pelos professores envolvidos no projeto. No entanto, no ambiente escolar existe uma "cultura" entre os estudantes de que somente aquilo que "vale nota" é feito com critério e rigor. Assim, as professoras estipularam valores mínimos e máximos para cada uma das etapas a serem cumpridas, a partir de critérios pré-estabelecidos. Mas, vale reforçar, que está pontuação não tinha, para elas, uma perspectiva quantitativa, mas sim qualitativa.

Como resultados deste projeto, além dos conhecimentos, habilidades e competências desenvolvidas, foi organizada uma exposição de arte, aberta ao público, com a exposição de painéis artísticos confeccionados a partir de sólidos geométricos construídos como diferentes 
materiais, segundo o conceito de Assemblage; o registro em fotos dos trabalhos; e a elaboração de artigos de opinião sobre os diferentes temas trabalhados visando à produção de um jornal escolar on-line.

\section{Desenvolvimento do trabalho}

O projeto foi estruturado em sete etapas, se estendendo de março a junho de 2010. Foi desenvolvido junto aos 120 estudantes (aproximadamente), das três turmas de $3^{\mathrm{a}}$ séries do ensino médio do período diurno de uma escola pública do estado de São Paulo, e envolveu quatro professoras, responsáveis pelas de disciplinas de Matemática (1), Língua Portuguesa (2) e Artes (1).

Os discentes, em cada classe, se organizaram em grupos de quatro elementos e, ainda em sala de aula, foram orientados em relação às atividades a serem desenvolvidas extraclasse. Em alguns momentos, eram trabalhados conteúdos de apoio em sala, dentro de uma abordagem baseada em pesquisa inicial feita pelos alunos, na perspectiva de resolver alguma situação-problema anteriormente proposta. Com isso, buscou-se levantar as suas concepções, conhecer os obstáculos epistemológicos que podiam interferir na aprendizagem antes de serem feitas intervenções, buscando suprir as lacunas de conhecimentos detectadas, auxiliando a aprendizagem.

Abaixo, estão descritas as etapas do trabalho, tendo como base as considerações de Hernández (1998) e de Gasparin (2009).

Num primeiro momento, a professora de Artes solicitou que os estudantes fizessem uma pesquisa a respeito das relações entre a Assemblage e o Cubismo. Esta atividade tinha como objetivos específicos que eles: buscassem informações acerca do tema; conhecessem e procurassem estabelecer relações entre esta técnica e o movimento artístico ao qual pertence; identificar os conhecimentos matemáticos necessários à quem se utiliza desta técnica. Após efetuarem as pesquisas, eles foram instigados a escrever um texto informativo inédito, com tamanho de uma página, a respeito do assunto estudado. Os trabalhos foram entregues à professora de Língua Portuguesa, que os corrigiu e esclareceu a respeito dos problemas detectados. Estes trabalhos foram avaliados de acordo com os seguintes critérios: apresentação clara e correta dos conceitos, existência de relações entre tais conceitos, obediência à norma culta e coerência interna.

Em seguida, os estudantes foram instruídos a fazer, com base em informações contidas no livro didático, a planificação de oito sólidos geométricos: cubo; cilindro; prismas de bases retangular, triangular e hexagonal; pirâmides de base quadrada e pentagonal; e um cone. Para cada grupo foi solicitado que os objetos fossem construídos com diferentes medidas, mas com orientações precisas que visavam manter, dentro de um mesmo grupo de 
sólidos, a proporção entre bases e alturas, visando comparações posteriores. Os trabalhos foram avaliados tendo como critérios: exatidão dos desenhos, das medidas solicitadas e uso adequado dos instrumentos (régua, lápis, compasso e esquadros).

Os grupos foram orientados a guardarem uma cópia planificada de cada um dos sólidos geométricos entregues anteriormente e, a partir delas, deveriam efetuar cálculos de área e volume para cada um deles. Para isso, eles foram orientados a buscar a teoria acerca dos conceitos e isso demandou que a professora os ajudasse, indicando referências para o trabalho. A ideia era que, após os cálculos efetuados, respondessem às seguintes situaçõesproblema, entre elas:

- Entre as pirâmides construídas, qual delas comporta maior volume?

- Entre os prismas construídos, qual necessita de maior espaço no papel para ser montado?

- Entre o cilindro e o cubo, qual deles comporta maior quantidade de água?

- Quais as justificativas teóricas para as constatações obtidas?

Nesta fase a docente não deu explicações pormenorizadas, visando incentivar a pesquisa e a discussão entre os componentes dos grupos, uma vez que estes conteúdos também já foram trabalhados em outras etapas da Educação Básica, ainda que em menor profundidade (efeito espiral).

Após a correção e de posse das lacunas conceituais apresentadas pelos grupos, a professora retomou parte dos conteúdos, corrigindo as questões problemáticas mais recorrentes na lousa, explicitando os erros detectados e apontando como superá-los. Depois, foram discutidos e resolvidos problemas retirados de provas do Exame nacional do Ensino Médio (ENEM), buscado mostrar como estes mesmos conteúdos são abordados em avaliações externas, explorando a linguagem técnica utilizada na elaboração das questões destas provas.

Em outra etapa, a docente que ministrava aulas de Educação Artística fez uma apresentação utilizando recursos de multimídia discorrendo a respeito da importância do conhecimento matemático para o desenvolvimento da Arquitetura e para Arte. Discutiu associações entre os conhecimentos matemáticos e o Renascimento, o Cubismo e a técnica de Assemblage. Partiu de uma revisão histórica, utilizando os monumentos construídos desde a antiguidade, passando pelas artes egípcia, grega, romana; retomou obras de arte importantes dos períodos Bizantino, Gótico, Renascimento, Barroco, Neoclassicismo, Impressionismo e o Cubismo. A ideia foi fazer uma retrospectiva mostrando como os conhecimentos ligados à Arte, à História e à Matemática estão interligados e que, em cada um dos momentos 
analisados, a Arte e a Ciência não são atividades neutras e nem desconexas: fazem parte de uma complexa rede de interesses políticos, econômicos e sociais.

A seguir, as professoras de Língua Portuguesa efetuaram uma orientação em sala de aula a respeito de como escrever um texto jornalístico: o artigo de opinião. Cada grupo de alunos deveria, em cada uma das turmas, efetuar pesquisas e elaborar textos versando sobre os seguintes temas: A Matemática e o Cubismo, $O$ uso das formas geométricas na Arquitetura, e As interfaces entre a Matemática e a Arte. Foram estabelecidas as normas para digitação de textos jornalísticos, visto que esses passariam por uma seleção para a publicação em uma edição do jornal que compunha o site da escola. Os trabalhos foram alvo de análise, discussão, correção e avaliação pelas professoras da área.

Finalmente, os grupos foram orientados a fazer a montagem dos trabalhos artísticos, respeitando os critérios teóricos sobre Assemblagem e da construção dos sólidos geométricos, que comporiam os painéis. Cada grupo poderia escolher, entre as diferentes figuras geométricas trabalhadas, aquelas que iriam compor seus trabalhos. Também optaram pelos materiais para sua montagem, cores, texturas e temas. Era época da Copa do Mundo, na África, e muitos dos trabalhos tiveram esse tema como central.

Cada um dos trabalhos deveria ser acompanhado por um texto explicativo sobre o que representava a obra, quais as intenções artísticas, uma vez que durante a exposição, aberta ao público, haveria sempre um componente de cada grupo para explicar ao expectador o projeto como um todo e a obra exposta. Os trabalhos foram montados em placas de compensado quadradas, medindo $40 \mathrm{~cm}$ e com um pequeno recuo interno, como se fosse uma moldura, de $10 \mathrm{~cm}$, tendo um apoio no verso (numa das arestas) para ser fixado no painel de exposição. Os trabalhos foram avaliados pelo grupo de professoras, de acordo com os critérios: tema, enredo, materiais, criatividade, técnica e composição de cores.

Cada grupo de alunos fotografou os diferentes trabalhos durante a exposição e entregou, como forma de avaliação, duas fotos impressas. Seis foram escolhidas pelos alunos e estas deveriam acompanhar os artigos a serem publicados no jornal on-line da escola. Infelizmente, com a reforma da sala de informática da unidade de ensino, tornou-se inviável o uso dos computadores e a fase final do trabalho foi prejudicada, uma vez que nem todos os estudantes dispunham de equipamentos pessoais para realização desta tarefa.

Assim, houve uma descaracterização da proposta inicial, pois o uso dos computadores permitiria um trabalho coletivo, onde os alunos mais experientes iriam compartilhar conhecimentos referentes à diagramação dos textos, ampliando as habilidades dos demais colegas. No entanto, um jornalista participou do vernissage e o artigo por ele escrito e publicado (O Debate, 2010) foi apresentado e discutido em sala de aula. 
A seguir estão algumas fotos dos painéis criados pelos alunos, feitas durante a montagem da exposição.

1- Foto de um dos painéis

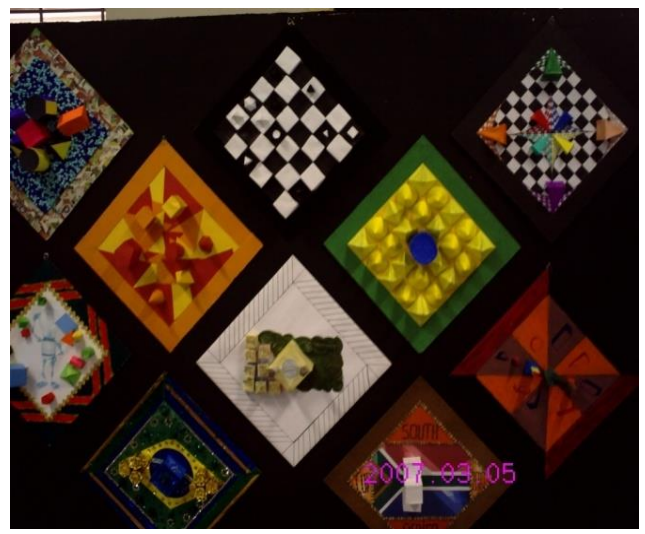

Arquivo pessoal
2- Foto dos trabalhos sobre a mesa

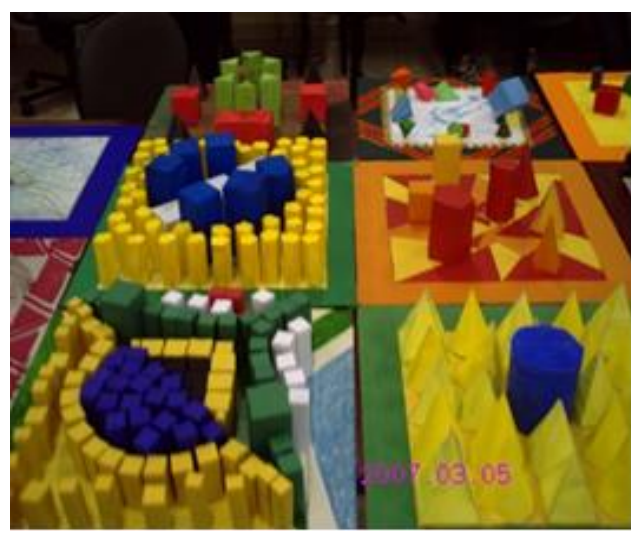

Arquivo pessoal

3- Foto dos trabalhos sobre a mesa

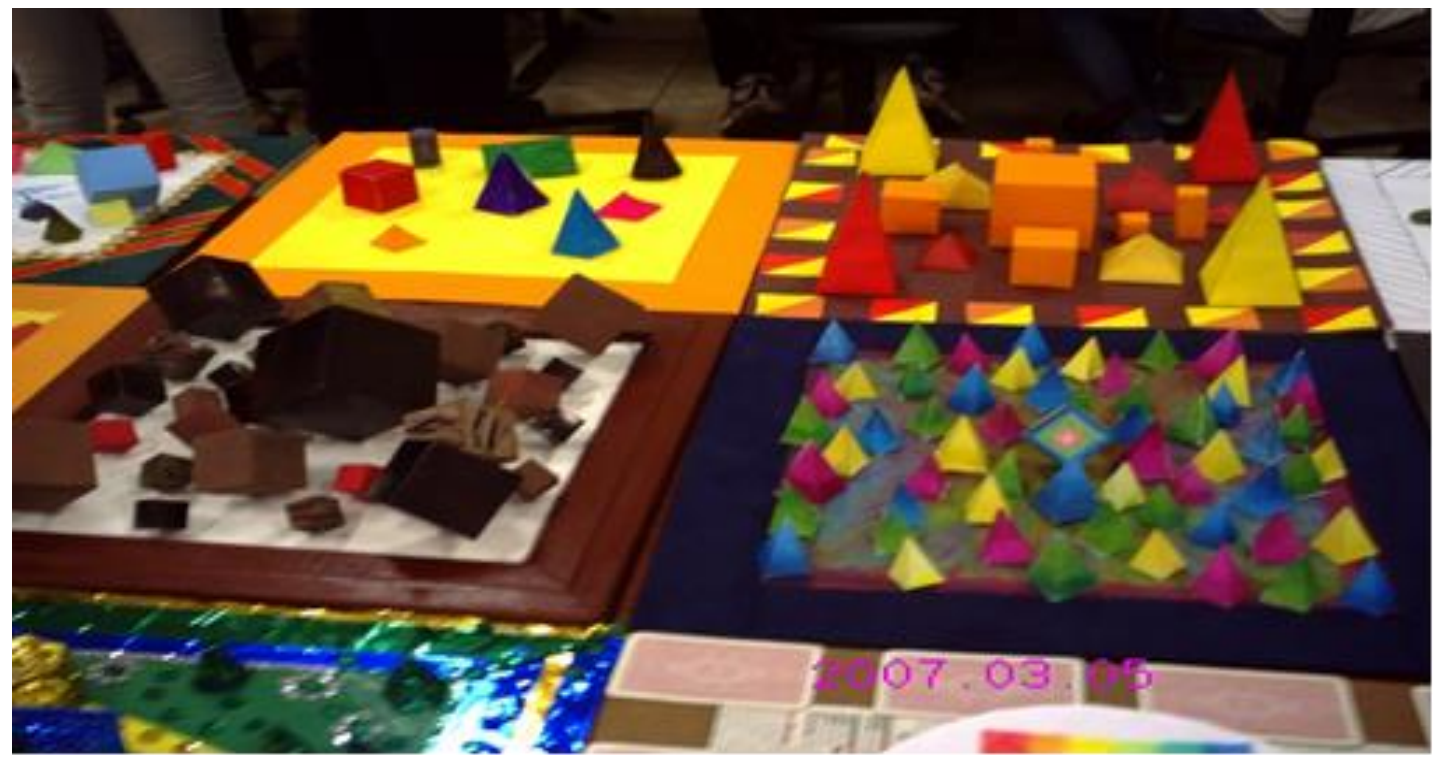

Arquivo pessoal

No final, os estudantes também fizeram uma autoavaliação, a partir questões-chave e também avaliaram a participação dos demais colegas (de forma anônima) em cada um dos grupos.

Cada uma das etapas cumpridas valiam de o a 2,5 pontos; a autoavaliação valia 1,5 pontos e a avaliação dos colegas 1,0 ponto. A pontuação máxima seria 20 pontos que, dividida por dois, representou uma das notas do $2^{\mathrm{O}}$ bimestre em cada uma das disciplinas envolvidas no projeto. 


\section{Considerações finais}

O grupo de docentes envolvidos na elaboração e na realização deste projeto de ensino evidenciaram alguns contrapontos acerca do trabalho com essa abordagem. Com frequência, o trabalho por meio de projetos é apreciado pelo fato de auxiliar na superação de distorções decorrentes da aplicação da pedagogia por objetivos, e isso pode ser observado a partir do desempenho dos estudantes durante e após o desenvolvimento do projeto, que foi bastante satisfatório.

Porém, constatamos em nossa prática que este tipo de abordagem apresenta alguns fatores limitantes. Entre eles, destacamos alguns:

1- o fator tempo: uma vez que com esta forma de abordagem necessita de mais tempo para o planejamento coletivo das ações docentes e para o desenvolvimento dos conteúdos, que tem início nas pesquisas, nos levantamento e preenchimento de falhas conceituais detectadas. Assim, nos parece inviável desenvolver todos os conteúdos anuais dentro desta perspectiva;

2- o fator formação: uma vez que existem lacunas de ordem didático-pedagógica dos professores que, sem a devida formação, podem organizar suas ações segundo o senso comum, ou mesmo dentro de um modelo de racionalidade técnica, pouco avançando em relação à práticas tradicionais de ensino;

3- a falta de recursos ligados à informática: uma vez que os computadores das escolas públicas, muitas vezes, se encontram sem condições de uso ou mesmo com acesso à internet bastante prejudicado; também fatores ligados à especificidade do uso dos recursos por parte de professores e estudantes.

No entanto, no caso aqui apresentado, os fatores positivos superaram os limitantes. Quanto aos conteúdos das diferentes disciplinas, os objetivos pretendidos nos planos de ensino, tanto o geral como os específicos, foram atingidos com a totalidade dos grupos de alunos, em diferentes graus de aprofundamento. Melhorias também foram percebidas em relação à aprendizagem de outros conteúdos, abordados posteriormente. A professora de Matemática, por exemplo, que atuava naquela mesma escola há mais de doze anos, concluiu que houve maior interesse, por parte dos estudantes, em aprofundar o nível de conhecimento ao compará-los com as turmas de anos anteriores e também melhor desenvoltura no aprendizado de novos conteúdos.

O envolvimento dos discentes com o projeto foi intenso; a qualidade dos trabalhos apresentados, tanto os painéis, quanto os artigos e as fotos, foi significativa; os grupos 
trabalharam de diferentes formas, buscando atingir as expectativas esperadas, desenvolvendo a autonomia, a organização e administrando os conflitos decorrentes do trabalho coletivo. De modo geral, as avaliações por eles realizadas apontam para pontos positivos desta forma de abordagem.

Quanto às docentes participantes, o trabalho proporcionou o estudo de diferentes textos visando a fundamentação teórica a respeito desta metodologia de ensino; puderam fazer experimentações; desenvolveram habilidades em relação a como elaborar e executar um trabalho interdisciplinar, aprofundando a reflexão crítica nos momentos que se fazia necessário um novo direcionamento para o planejamento. Também propiciou momentos que estreitaram relações entre si e com estudantes, uma vez que esta forma de trabalho possibilita uma maior proximidade entre os envolvidos, favorecendo as relações interpessoais e conhecimentos a respeito de características pessoais que, na forma tradicional de ensino, são mais difíceis de serem percebidas.

Sabe-se que não existe um caminho que seja único, ou melhor, ou mais correto para realização de um projeto de ensino. Assim, acreditamos que a grande preocupação dos docentes que se predispõem a este tipo de trabalho deva concentrar-se na articulação entre a intencionalidade, os conteúdos, a realidade e a mediação. Neste sentido, faz-se necessário, além de conhecer os conteúdos a serem ensinados e o processo de transposição didática dos mesmos, buscar teorias que fundamentem estas práticas e, efetuando uma prática reflexiva, realimentar as teorias a partir do relato e divulgação de saberes experienciais.

\section{Referências}

BRASIL. Secretaria da Educação Básica. Ciências da Natureza, Matemática e suas Tecnologias. Orientações curriculares para o ensino médio, v.2. MEC, Brasília, 2006.

GASPARIN, J. L. Uma didática para a Pedagogia Histórico-Crítica. Campinas, SP: Autores Associados, 2009.

HERNÁNDEZ, F. Transgressão e Mudança na Educação os projetos de trabalho. Porto Alegre: ArtMed, 1998.

HERÁNDEZ, F; VENTURA, M. A Organização do currículo por projetos de trabalho: o conhecimento é um caleidoscópio. Porto Alegre: Artmed, 1998.

Jornal O Debate. http://www2.uol.com.br/debate/1526/index.htm. Acesso em 09/05/2013.

KUENZER, A. (Org.). Ensino Médio: construindo uma proposta para os que vivem do trabalho. $5^{\mathrm{a}}$ ed. São Paulo: Cortez, 2007.

GARDNER, H. Estruturas da mente: a Teoria das Múltiplas Inteligências. Porto Alegre: Artes Médicas, 1994. 
GAUTHIER, C. et al. Por uma teoria da pedagogia: pesquisas contemporâneas sobre o saber docente. Ijuí: UNIJUÍ, 1998.

SÃO PAULO. Secretaria de Estado da Educação. Currículo do Estado de São Paulo: ciências da natureza e suas tecnologias. São Paulo: SE, 2012, 152p.

SCHÖN, D. A. Educando o profissional reflexivo: um novo design para o ensino e a aprendizagem. Porto Alegre: Artes Médicas, 2000.

TARDIF, M. Saberes docentes e formação profissional. $7^{\mathrm{a}}$. ed. Petrópolis, RJ: Vozes, 2002

VASCONCELLOS, C. dos S. Planejamento: projeto de ensino aprendizagem e projeto político-pedagógico_elementos metodológicos para elaboração e realização. $14^{\mathrm{a}} \mathrm{ed}$. Libertad Editora, 2005.

VYGOTSKY, L.S. Pensamento e Linguagem. São Paulo, Martins Fontes, 1989.

\section{Agradecimentos}

Agradecemos às colaboradoras que participaram ativamente da execução das atividades analisadas: Rita de Cássia F.G.Vito; Marli Ap. C. dos Santos; Paula Berenice Souza.

\section{Biografia Resumida}

Beatriz Salemme Corrêa Cortela, Licenciada em Física pela Universidade Federal de São Carlos (UFSCar_SP) e em Matemática pela Universidade Estadual do Norte do Paraná (UENP); Prof. Assist. Dr. do Departamento de Educação e docente do Programa de Pós-Graduação em Educação para Ciência, Faculdade de Ciências, UNESP, Bauru.

e-mail: biacortela@fc.unesp.br 